\title{
Binge-Eating Disorder:
}

\section{Clinical Foundations and Treatment}

by James E. Mitchell, MD; Michael J. Devlin, MD; Martina de Zwaan, MD; Scott J. Crow, MD; and Carol B. Peterson, PhD. The Guilford Press, New York, NY, 2008, 214 pages, \$30.00 (trade paper).

The conundrum as to whether binge-eating disorder (BED) should be a separate diagnosis or whether it should continue to be part of eating disorder not otherwise specified is not solved in this book. Part 1 is a literature review of BED and Part 2, the most valuable section for clinicians, is a detailed manual for cognitivebehavioral treatment for BED. The latter has been tested in controlled treatment trials and shown to be effective.

Part 1 contains useful information on the clinical features of $\mathrm{BED}$, the relationship of obesity to BED, and an evaluation of different treatment methodologies. There is also a section on bariatric surgery for patients with obesity and BED.

In summary, this book contains concise and useful information for the clinician and a practical manualized cognitive-behavioral treatment for BED.

Katherine A. Halmi, MD kah29@cornell.edu

Author affiliation: Weill Cornell Medical College, New York, New York. Potential conflicts of interest: None reported.

doi:10.4088/JCP.09bk05576whi

(c) Copyright 2010 Physicians Postgraduate Press, Inc. 